(6) OPEN ACCESS

Defence Science and Technology Laboratory, Porton Down, UK

Correspondence to Mrs Fiona Butcher, Defence Scientific and Technology Laboratory, Porton Down, Salisbury, Wiltshire, P017 6AD UK; FDBUTCHER@dstl.gov.uk

Received 20 August 2018 Accepted 21 September 2018 Published Online First 14 November 2018

Check for updates

Dstl Publication, DSTL/ JA111692 (2019). Crown Copyright (C) 2019 Dstl

To cite: Butcher F. J R Army Med Corps 2019:165:113-115.

\title{
Role of research psychology in defence and security
}

\author{
Fiona Butcher
}

\section{ABSTRACT}

The following article provides an overview of the research psychology capabilities within MOD's Defence Science Technology Laboratory (Dstl). An explanation is provided of the role of Dstl psychologists and the way they work to deliver impacting applied scientific research to address 'real world' defence and security challenges. Three short case studies are provided to illustrate the range of work they delivered.

\section{INTRODUCTION}

During the Second World War, a Ministerial Committee was established to review psychiatric and psychological work being conducted in the three Services and to make recommendations for the future development and improvement of this work. As part of this work, a subcommittee report was published in 1945 which identified a broad range of areas where psychologists could help including the development of tests for detecting the unfit, selecting officers and for measuring special aptitudes or trade knowledge. Other domains noted for psychologists involved conducting assessments of visual and auditory perception to identify how people can effectively detect aeroplanes, submarines and methods of camouflage. ${ }^{1}$ Finally, the report notes that the role of psychologists in these areas would enhance the understanding of how to effectively communicate with the public to aid recruitment in the UK, influence those in adversary countries and work to support postwar problems, including education, rehabilitation and occupational therapy. ${ }^{2}$

In today's global defence and security environment, research psychologists continue to build the research evidence base in order to be able to provide advice to senior decision-makers across a similar range of topics. The largest group of applied research psychologists within the MOD are in the Defence Science Technology Laboratory's Human and Social Sciences Group and the following article aims to describe the role of these psychologists, and using examples, demonstrate the impact of the applied psychology research that they deliver.

\section{WHAT IS THE DEFENCE SCIENCE TECHNOLOGY LABORATORY?}

The Defence Science Technology Laboratory (Dstl) delivers high-impact Science and Technology (S\&T) for the UK's defence, security and prosperity. The role of the Dstl's scientists and analysts is to act as trusted advisors in order to:

- Deliver S\&T for defence and security.

- Maximise impact and value from the S\&T Portfolio.
Key messages

The following article describes the role of MOD's Defence Science and Technology Laboratory (Dstl) and the way impactful research is delivered in collaboration with industry and academia.

- There are approximately 70 research psychologists in Dstl that draw upon recognised areas of psychological science such as neuro, cognitive, social, biological and behavioural psychology; and include psychologists from professional groups such as forensic, occupational and health psychology.

- To illustrate the breadth of the research challenges Dstl psychologists three examples are summarised. The projects include research to develop interventions to improve crosscultural communication in Afghanistan, improving the understanding of violent extremist behaviours and the application of future technology to enhance human capability.

- Supply specialist S\&T services which must be done in government.

- Provide expert and impartial advice, analysis and assurance.

- Integrate S\&T delivered by industry, academia, wider government and its allies.

- Steward defence and security S\&T capabilities.

- Ensure the required capabilities are available now and in the future in line with the S\&T Strategy.

- Bring together the right people, relationships, infrastructure, knowledge and licences to practise.

- Maximise the effectiveness and efficiency of our S\&T infrastructure and assets.

- Work with industry, academia, wider government and its allies to access and build capability.

- Act as a trusted interface between the MOD, wider government, the private sector, academia and allies to support military co-operation, capability delivery, diplomacy and economic policy. (This includes the Dstl's role in international research co-operation activities.)

- Champion and develop science and technology skills across the MOD, including managing the careers of Dstl scientists.

How do psychologists work in Dstl?

There are approximately 70 research psychologists in Dstl that draw on recognised areas of psychological science such as neuro, cognitive, social, biological and behavioural psychology and include 
psychologists from professional groups such as forensic, occupational and health psychology. The human sciences related research delivered by Dstl benefits from a broad and vibrant academic and commercial supply chain that Dstl psychologists harness to deliver their research.

Within the organisation, the Dstl psychologists work in an interdisciplinary, problem-focussed way, functioning as part of multidiscipline applied research teams, together with other Dstl personnel from a broad range of science, technology and analysis disciplines. Beyond a few sensitive and specialist capabilities retained within government, a Dstl psychologist's role primarily focuses on enabling the MOD and wider government to access the science base. This is achieved by translating customer needs into science and technology issues that can be addressed in collaboration with academia and industry. As well as supporting supplier teams who are delivering work, Dstl psychologists translate their scientific work into a language that MOD stakeholders can then use to inform decisions.

\section{What kind of research challenges does a Dstl psychologist address?}

The research challenges that Dstl psychologists address are complex 'real world' problems that require investigation from a number of different perspectives; which is why Dstl takes a interdisciplinary research approach, in order to provide research outputs that can be readily applied in the operational environment as well as inform future defence and security strategy and policy. In this Special Edition of the Journal of the Royal Army Medical Corps (JRAMC), several articles from Dstl psychological scientists provide examples of cognitive and human factors research. Such papers examine the applied psychological variables that underpin performance improvements in Counter-Improvised Explosive Device Specialist Search Teams ${ }^{3}$ and health psychology research that has informed MOD strategy and policy in the area of risk propensity and health behaviours of deployed UK army personnel. ${ }^{4}$ However, to illustrate the breadth of the research challenges, Dstl psychologists address across their duties, the following three examples consider domains that are current for the MOD's research psychologists, namely cross-cultural communication, counter-terrorism and the application of future technology to enhance human capability.

\section{The challenge: de-escalating 'Insider Attacks'}

Since the end of the Cold War, the UK Armed Forces are increasingly involved in peacekeeping and peace-enforcement operations, in addition to expeditionary warfare deployments. Such missions involve UK personnel increasingly embedded as part of coalition forces. These operations require close interaction with local populations and non-UK military formations. During recent operations in Afghanistan, there was an escalation in Insider Attacks (sometimes referred to as 'Green-on-Blue'). The term 'Insider Attack' was used when a member of the Afghan National Security Forces attacked members of the International Security and Assistance Force, of which the UK was a part.

Dstl psychologists carried out research using data collected by Dstl operational analysts deployed in Afghanistan ${ }^{5}$ and an analysis of past incidents. They sought to establish whether there were any trends or themes that could be identified to better understand why the attacks occurred. In addition, through partnership with commercial suppliers, experimental trials were conducted to validate commercial training courses that could supplement the predeployment training provided to military personnel. A key aspect of the research was to increase understanding of how to dissuade people from engaging in Insider Attacks and identify methods of reducing the chances of a situation escalating in such a manner.

This was high tempo, which sought to respond to current operational needs. The research delivered short-term and medium-term advice and training solutions during a period when there was a significant spike in insider attacks against UK military personnel. The training solution that was recommended was seen first-hand by military personnel serving in Afghanistan, including the Commander of Task Force Helmand in 2012/2013, who personally endorsed its value, and the work of the team was attributed to contributing to the steady reduction in Insider Attacks in the later HERRICK period (Dstl, p. 28). ${ }^{6}$

\section{The challenge: distinguishing between violent and non-} violent extremists

In addition to supporting military activities, Dstl psychologists provide research and advice to inform defence and security professionals responsible for addressing countering terrorism (CT) threats. Over the years, this has included informing the national security contingency planning for the London 2012 Olympics and safe travel on the UK transport system. ${ }^{7}$ More recently Dstl has undertaken an empirical study to compare violent extremists (VEs) and non-violent extremists (NVEs) to inform CT practitioners and policymakers on the development of appropriately tailored interventions for different types of extremist individuals or groups. The study aimed to address the unresolved question of: why some people with extreme views are prepared to commit acts of violence while others, with similar views, are not? In-depth case studies on 40 extremist individuals were developed and analysed to identify the key themes, subthemes and underlying variables. This analysis enabled an understanding of where there may be similarities and differences between VEs and NVEs as well as identify variables that could help distinguish between these two types of extremist. ${ }^{8}$ It is now planned to use the results from this recently published work to develop a risk assessment tool that can be used by CT practitioners.

The challenge: effective future working between humans and intelligent machines

The 2015 Security and Defence Strategic Review ${ }^{9}$ highlighted that Britain's competitive advantage will continue to be based on the quality of our Defence people and emphasised the need for high levels of innovation in order to maintain our operational advantage. However, it is recognised that technology advances such as autonomous systems and Artificial Intelligence offer both opportunities and challenges for Defence's future people capabilities impacting future strategy, policy and working practices. ${ }^{10}$

To address this future challenge, Dstl psychologists are working in partnership with industry and academia to develop state-of-the-art S\&T prototypes to enhance personnel performance. Concepts that are being tested include machines teamed with humans during training. For example, a 'virtual assistant' could provide personalised training in the classroom and also in the field and could even potentially sense a human's emotional state. To test these future-focussed concepts, prototypes are being assessed in human participant laboratory experiments using realworld scenarios. ${ }^{11}{ }^{12}$ Another growing area of research entails the development of training and policy initiatives to enhance the mental resilience, motivation and decision-making processes of military personnel, including those of psychologists working in military settings. ${ }^{13}$ Such scientific work will ensure that personnel 
are 'change ready' for the future complex evolving environments in which service members will need to operate. ${ }^{14}$ These ongoing research studies have already informed Defence Future Concepts $\left(\right.$ see $\mathrm{DCDC}^{15}$ ) and Defence strategic thinking.

\section{CONCLUSION}

This article has outlined how Dstl research psychologists work to address the broad range of research challenges that UK Defence faces today and in the future. As we commemorate 100 years since the end of the First World War, it is interesting to see that while the military operate in a more technologically advanced environment, developing and protecting our people remains at the core of the MOD's Science and Technology Strategy (see Ministry of Defence, p. 24). ${ }^{16}$ As a result, research psychology will continue to cover a broad range of topics, similar to those identified in the Ministerial subcommittee's 1945 report. However, today we have a larger science and technology base and access to new techniques, (including technology enabled data collection methods and smart qualitative and quantitative analysis), to enable us to deliver against increasingly complex Defence challenges.

Correction notice This article has been corrected since it was published Online First. The 'Correspondence to' address was incorrect and abbreviation of 'Dstl' was also incorrect throughout the article.

Acknowledgements The author would like to thank colleagues within Dstl for the useful discussions that informed this paper. In addition, the paper benefitted significantly from comments received during the Dstl technical review process as well as the comments from the JRAMC review.

Funding The authors have not declared a specific grant for this research from any funding agency in the public, commercial or not-for-profit sectors.

Competing interests None declared.

Patient consent Not required.

Provenance and peer review Commissioned; internally peer reviewed.

Open access This information is licensed under the UK Open Government Licence v3 (to view this licence, visit http://www.nationalarchives.gov.uk/doc/ opengovernment-licence/version/3 or write to the Information Policy Team, The National Archives, Kew, London TW9 4DU, or email: psi@nationalarchives.gsi.gov.uk). The contents of this document should not be interpreted as representing the views of the UK MOD, nor should it be assumed that they reflect any current or future UK MOD policy. The information contained in this document cannot supersede any statutory or contractual requirements or liabilities and is offered without prejudice or commitment.

\section{REFERENCES}

1 Olson T, McCauley M, Kennedy C. History of aeromedical psychology. In: Kennedy C, Kay G, eds. Aeromedical psychology. Farnham, UK: Ashgate Publications, 2013: 1-17.

2 Hacker-Hughes J. Resilience through change : a centh Change: a century of British military psychology 1915-2015. BPS 4th military psychology conference, 2015.

3 Cornes KR, Boardman M, Ford C. Psychology, risk, health and deployed military operations. Adopting a systems approach to maximising performance during military visual search tasks, 2018

4 Verrall N. Psychology, risk, health and deployed military operations. Journal Royal Army Medical Corps 2018

5 Mikulskis DF, Butcher FD. Afghan perceptions of ISAF - difficult questions, international symposium of military operational research. MOD (2017), science and technology strategy. 2013. Available from: https://www.gov.uk/government/uploads/ system/uploads/attachment_data/file/655514/Science_and_Technology_Strategy_ lowres.pdf

6 Dstl. Annual report and accounts 2014/15. 2015. Available from: https://www.gov.uk/ government/publications/defence-science-and-technology-laboratory-annual-reportand-accounts-2014-to-2015

7 Butcher FD. Psychological research in defence and security. Applied psychology in the armed forces: current provision. Invited Symposium, British Psychological Society Annual Conference, 2014

8 Knight S, Woodward K, Lancaster GLJ. Violent versus nonviolent actors: an empirical study of different types of extremism. Journal of Threat Assessment and Management 2017:4:230-48.

9 UK National Security Strategy. National security strategy and strategic defence and security review 2015. 2015. Available from: https://www.gov.uk/government/ publications/national-security-strategy-and-strategic-defence-and-security-review2015

10 Yates S, 2016. Automation of future roles. Available from: https://waysofbeingdigital. files.wordpress.com/2017/09/outcomes-report-esrc-and-dstl-workshop-final.pdf

11 Pereira S, Hone K. Media skills training intervention based on automated recognition of human emotion and non-verbal behaviour. Brunel University PhD Poster Conference, 2017.

12 Colecchia F, Giacomin J, Hone K. A preliminary investigation towards the development of an emotion-aware partner agent for training control. Ergonomics and human factors conference, 2018.

13 McCauley M, Hughes JH, Liebling-Kalifani H. Ethical considerations for military clinical psychologists: a review of selected literature. Military Psychology 2008;20:7-20.

14 Carter A. Conference of European association of work and organizational psychology. In: Strategic change readiness: proposing a new multi-level construct. enabling change through work and organizational psychology, 2017.

15 DCDC. Future force concept, joint concept note 1-17. 2017. Available from: https:// www.gov.uk/government/publications/future-force-concept-jen-117

16 Ministry of Defence, 2017. MOD science and technology strategy 2017. Available from: https://www.gov.uk/government/publications/mod-science-and-technologystrategy-2017 